\title{
DIRECT LEFT ATRIAL PRESSURE TRACINGS AND THE DEGREE OF MITRAL OBSTRUCTION
}

\author{
BY \\ STANLEY R. MCCAMPBELL \\ From the Postgraduate Medical School and the Department of Medicine, Hammersmith Hospital \\ Received August 8, 1957
}

Attempts have been made to assess the degree of mitral obstruction in mitral stenosis by analysing the diastolic part of indirect left atrial pressure tracings (Owen and Wood, 1955). These pressure tracings have been obtained using a cardiac catheter in the pulmonary artery in the "wedge" position, and available evidence suggests that direct left atrial pressure tracings are comparable to indirect tracings in this measurement (Connolly et al., 1953; Owen and Wood, 1955; Dickens et al., 1957). Owen and Wood (1955) state that the behaviour of the $y$ descent (or $R y / v^{*}$ ) provides evidence of the presence or absence of obstruction at the mitral orifice, a slow $y$ descent suggesting obstruction, and a sharp $y$ descent absence of obstruction. The present study is an attempt to analyse $R y / v$ in cases of surgically proven mitral stenosis before and after mitral valvotomy.

\section{Material AND Methods}

Left atrial pressure tracings were made at the time of mitral valvotomy with the chest and pericardium open, through a 19 gauge needle on the end of a \#8 U.S. saline-filled catheter. The manometers used were of the conductance type and set with zero pressure referred to the sternal angle. D.C. amplifiers and mirror galvanometers were used. Records were made photographically before and after mitral valvotomy, and $R y / v$ calculated for each case by the method described by Owen and Wood (1955).

The patients represent a consecutive series of mitral valvotomies performed during the last three years at Hammersmith Hospital under the direction of Mr. W. P. Cleland. The estimation of mitral valve size and the presence or absence of mitral regurgitation were noted by the surgeon at the time of operation in each case. The patients are divided for purposes of discussion into two groups: (i) those without mitral regurgitation, and (ii) those with slight or moderate mitral regurgitation.

\section{RESULTS}

Fig. 1 shows a graph of $R y / v$ and its relationship to mitral valve size; it relates to 75 measurements in 48 patients without mitral regurgitation. Forty-eight of the measurements were made before valvotomy and 27 measurements following valvotomy. The correlation coefficient is +0.255 , which is significant $(0.05>P>0.01)$. It is, however, unimportant, since only 6.5 per cent of the variation in $R y / v$ can be accounted for by variation in valve size. Thus, if $R y / v=0 \cdot 5$, the valve size predicted from these figures could range from -0.38 to $3.10 \mathrm{~cm} .^{2}$.

* $R y / v$ is the rate of descent of the $y$ wave related to the filling pressure, $v . R y / v=\frac{(\mathrm{P} 1-\mathrm{P} 2) \mathrm{mm} \text {. }}{\mathrm{P} 1 \mathrm{~mm} . \times(\mathrm{T} 2-\mathrm{T} 1) \mathrm{sec}}$

Where $\mathrm{P} 1=$ Pressure at peak of $v$ wave.

$\mathrm{P} 2=$ Pressure at the end of the fall of $y$ wave.

$\mathrm{T} 2=$ Time at the end of the fall of $y$ wave.

$\mathrm{T} 1=$ Time at the peak of $v$ wave. 


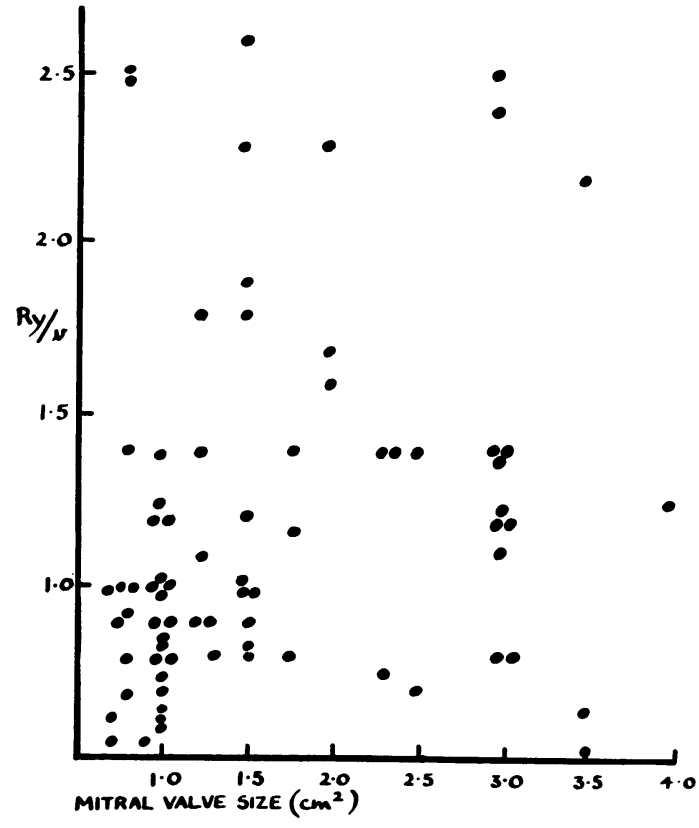

Fig. 1.-Relationship of $R y / v$ to mitral valve size in a group of patients without mitral regurgitation.

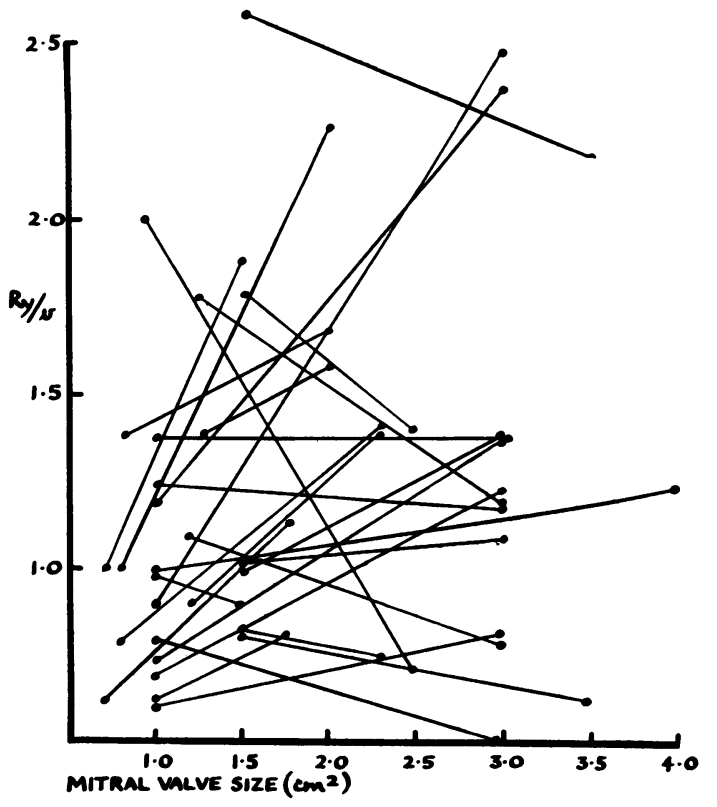

Fig. 2.-Relationship of $R y / v$ to mitral valve size before and after mitral valvotomy in the absence of mitral regurgitation.

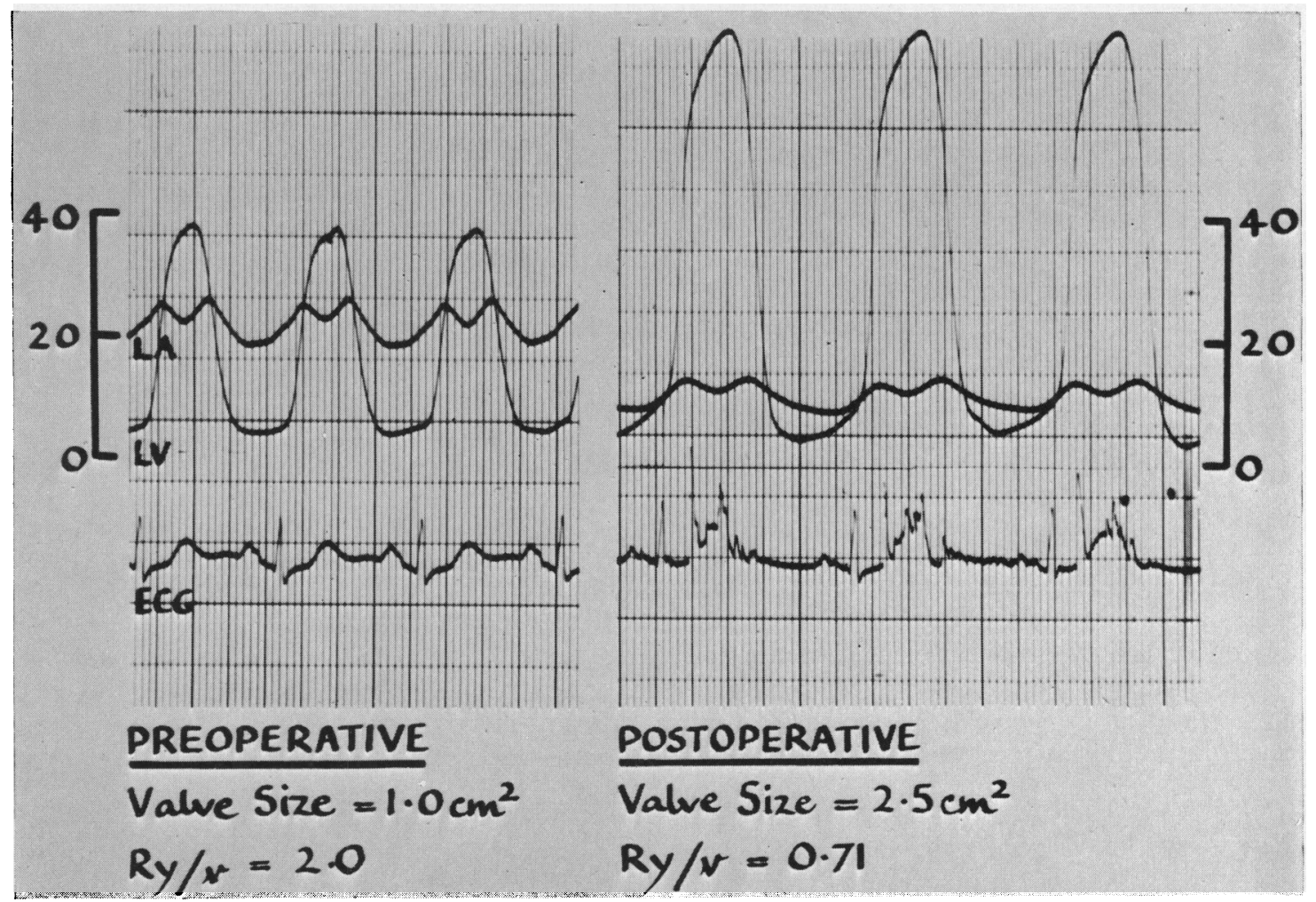

Fig. 3.-Left atrial and left ventricular pressure tracings in a case of tight mitral stenosis before and after mitral valvotomy. Note the change in heart rate. Simultaneous left ventricular pressure tracings are recorded here on a different scale. 
It may be seen from the graph that given a figure for $R y / v$ of $2 \cdot 5$, the mitral valve size in this series ranged from 0.8 to $3.0 \mathrm{~cm} .^{2}$. With a mitral valve size of $0.8 \mathrm{~cm} .{ }^{2}$ the $R y / v$ ranged from 0.7 to $2 \cdot 5$. Similarly, with a valve size of $3.5 \mathrm{~cm} .{ }^{2}, R y / v$ ranged from 0.5 to 2.2 . It is true that in the group whose valve measured less than $1.5 \mathrm{~cm} .^{2}, R y / v$ was less than 1.5 in 86 per cent, but in the group with valve size over $2.5 \mathrm{~cm} .{ }^{2}$ (and thus no hæmodynamically significant stenosis), 79 per cent had $R y / v$ figures of less than $1 \cdot 5$. It is difficult to see how these values would be worthwhile in estimating the degree of mitral stenosis in a single case.

If $R y / v$ were a measure of mitral valve obstruction, values for $R y / v$ would be expected to rise sharply following mitral valvotomy. Fig. 2 shows the behaviour of $R y / v$ before and after mitral valvotomy in 27 consecutive cases of mitral stenosis in which mitral regurgitation was judged by the surgeon to be absent both before and after valvotomy. $R y / v$ increased in 16 , decreased in 10 , and

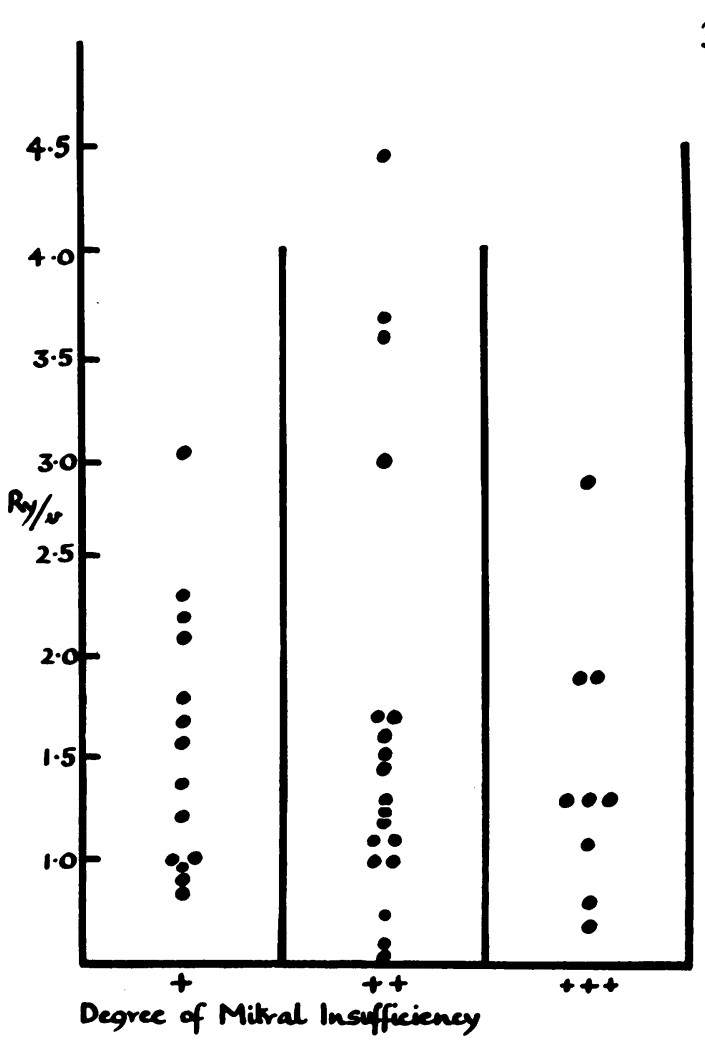

Fig. 4.-Relationship of $R y / v$ to the degree of mitral regurgitation.

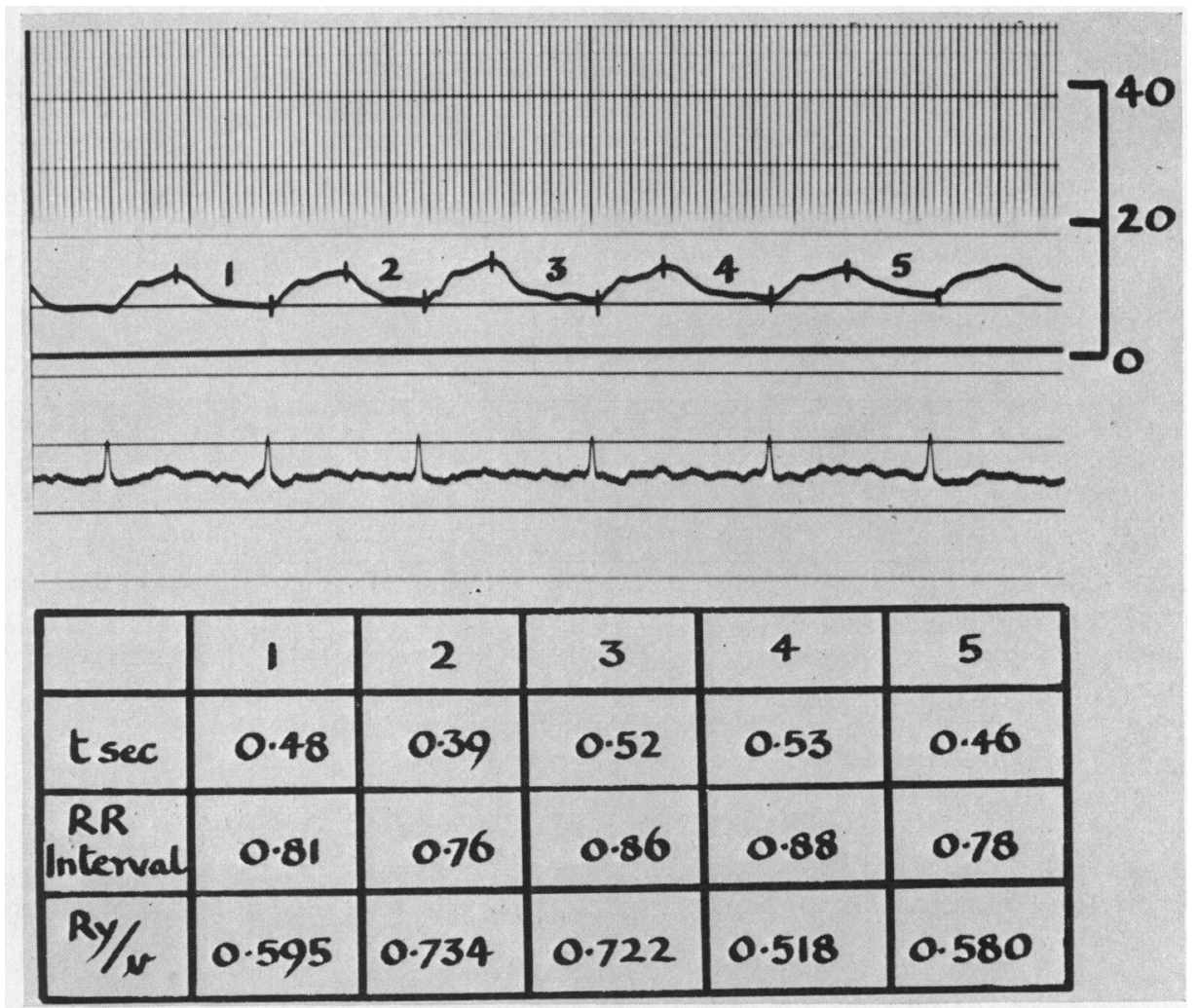

FIG. 5.-Left atrial pressure tracing in a patient with mitral stenosis and atrial fibrillation, showing the variation from one cardiac cycle to another in $t$ and $R y / v$. 
remained unchanged in 1. Fig. 3 shows an example before and after valvotomy in which $R y / v$ fell from 2.0 before to 0.71 after valvotomy. It is possible that the manipulation of the heart or left atrial suturing after valvotomy invalidate the immediate post-operative measurements of dynamic left atrial pressure. Certainly there are changes in blood flow associated with an adequate mitral valvotomy, which may invalidate measurement of $R y / v$. But the lack of a more consistent change in $R y / v$ following valvotomy suggests that $R y / v$ is influenced by many factors other than mitral valve obstruction, and that the measurement is of little value in estimating the adequacy of the valvotomy in the theatre.

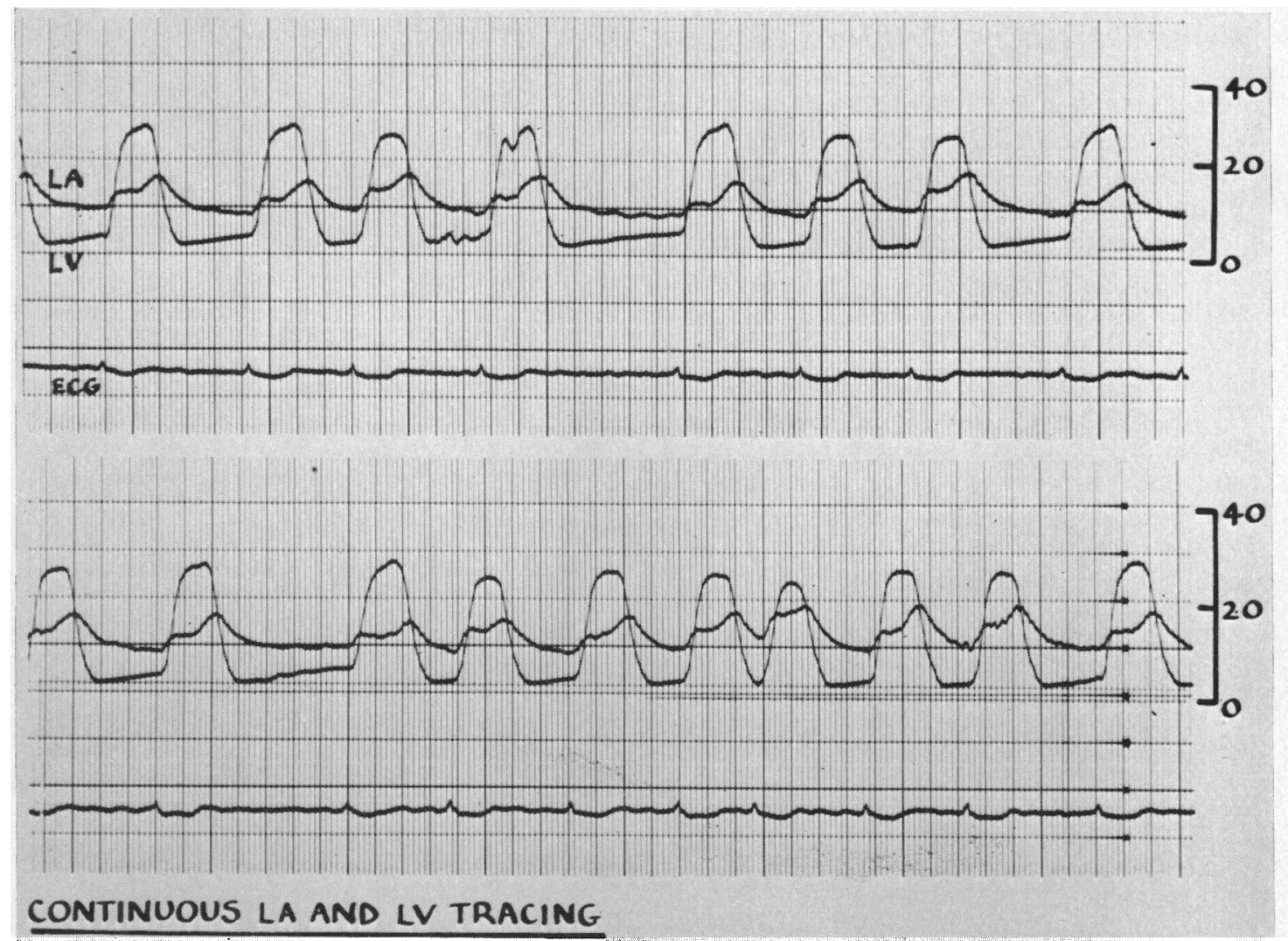

FIG. 6. - Left atrial pressure tracing $(0 / 40)$ and left ventricular pressure tracing $(0 / 100)$ with electrocardiogram in a case of mitral stenosis with atrial fibrillation, showing the extreme variations of $t$ with variations in RR interval in the record. See also Fig. 7.

A graph of $R y / v$ and the degree of mitral regurgitation in 43 patients in whom varying degrees of mitral regurgitation were judged to be present is shown in Fig. 4. There is no correlation between the degree of mitral regurgitation and $R y / v$. 42 per cent of the patients with moderate mitral regurgitation have figures for $R y / v$ of 1.5 or less. Thus $R y / v$ seems to be of little use in separating the patients with tight mitral stenosis from those with mild stenosis, from those with no stenosis, and from those with various degrees of coexisting mitral regurgitation.

\section{Discussion AND CONCLUSIONS}

An analysis of the rate of fall of the diastolic portion of left atrial pressure tracings would seem logically to give a measure of obstruction at the mitral valve. That this, in fact, does not prove to 
be the case in practice may be related to several factors. Measurements of small changes in pressure over a short time interval are probably poorly reflected in currently used measuring devices. The factor of blood flow, which is intimately related to pressures recorded (Dickens et al., 1957), is not analysed. The accurate determination of $R y / v$ in any single pressure tracing is made difficult by the frequent presence of atrial fibrillation and thus differences in cycle lengths and pressure levels (Fig. 5). Even the average of ten consecutive complexes does not seem to be wholly adequate in estimating $R y / v$. The time ( $\mathrm{t} 2-\mathrm{t} 1)$ from the top of the $v$ wave to the end of the fall $(y)$ is a function of heart rate (Fig. 6 and 7); and, since it is a fractional number in the numerator of the $R y / v$ formula, a small change in time $(t)$ related to heart rate could account for a large change in $R y / v$ without a change in obstruction of the mitral valve.

The above factors were controlled as carefully as possible in this study. However, the use of $R y / v$ in individual cases at operation does not seem valuable, since it does not differentiate either the degree of mitral stenosis or the presence or absence of a significant degree of mitral regurgitation under these circumstances. This would cast some doubt on the validity of this formula in other circumstances.

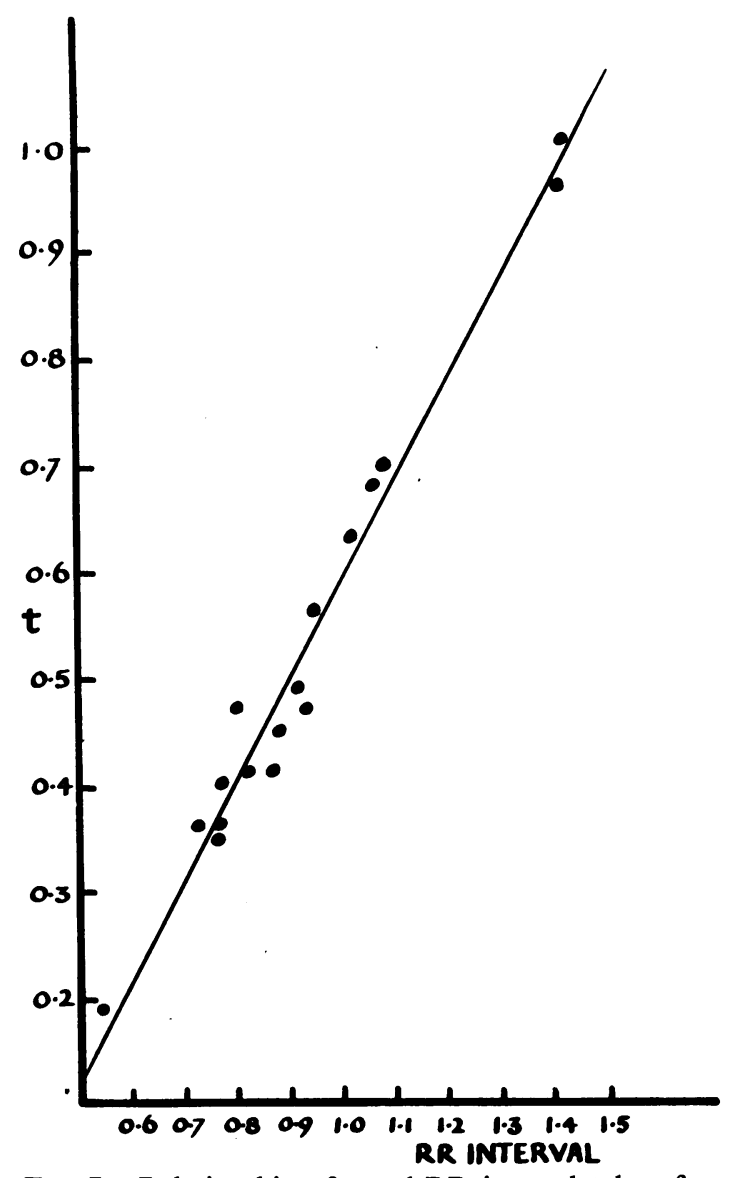

FIG. 7.-Relationship of $t$ and RR interval taken from 17 consecutive cycles in the case illustrated in Fig. 6, showing a linear relationship between $t$ and RR interval.

\section{SUMMARY}

An analysis of the diastolic part of left atrial pressure tracings $(R y / v)$ taken at the time of mitral valvotomy, showed a poor correlation with the degree of mitral obstruction and also with the presence or absence of mitral regurgitation. The measurement of $R y / v$ at operation was of little or no value in assessment of the degree of mitral obstruction or the adequacy of the valvotomy.

I wish to thank Mr. John Robson of the Department of Surgery for technical assistance in the preparation of this study.

\section{REFERENCES}

Connolly, D. C., Thompkins, R. G., Lev, R., Kirklin, J. W., and Wood, E. H. (1953). Proc. Staff Meet., Mayo Clinic, $28,72$.

Dickens, J., Raber, G., Woldow, A., Lorange, G. C., and Goldberg, H. (1957). New Engl. J. Med., $256,1017$.

Owen, S. G., and Wood, P. (1955). Brit. Heart J., 17, 41. 